\title{
Contribuição ao campo de usuários da informação: em busca dos paradoxos das práticas informacionais
}

\author{
Contribution to the field of information users: looking \\ for the paradoxes of information practices
}

Flávia Virgínia Melo PINTO'

Carlos Alberto Ávila ARAÚJO²

\section{Resumo}

Pretende-se debater as concepções teórico-metodológicas dos estudos de usuários da informação, criticamente, considerando a historicidade, a totalidade e as contradições da sociedade capitalista como constituidoras das práticas informacionais dos sujeitos. As atuais abordagens de estudos de usuários da informação, tradicionais e alternativas, mostram-se limitadas por não abarcarem a complexidade dos aspectos que formam os sujeitos e a sua constituição social. Desconsideram a dimensão histórico-social da ação humana, focando somente a ação individual. Entende-se que, para compreender as práticas informacionais dos sujeitos, é necessário situá-las historicamente, considerando-se que a subjetividade não está descolada da estrutura social. Para a construção de um método ou de uma forma de olhar crítica, sugere-se a adoção de categorias de análise desenvolvidas por Pierre Bourdieu. Apresentam-se as categorias habitus, campo social e capital simbólico para tentar compreender as práticas informacionais construídas no cruzamento entre as relações sociais baseadas na exploração de uma classe sobre outra (e de dominação de um grupo sobre outro) e compreender também a percepção subjetiva dos indivíduos.

Palavras-chave: Método. Práticas informacionais. Usuários da informação.

\begin{abstract}
The article critically discusses the theoretical and methodological concepts of the studies of information users, considering the historicality, totality and the contradictions of capitalist society as constitutors of the informational practices of users. The current traditional and alternative approaches to information users have been shown to be limited, because they do not cover the complexity of the aspects that shape the users and their social constitution. These theories disregard the historical-social dimension of human action, focusing only on the individual action. One understands that to comprehend the informational practices of subjects, it is necessary to put them into historical perspective, considering that subjectivity is not separated from the social structure. In order to build a method or a critical point of view, the adoption of the categories of analysis developed by Pierre Bourdieu is suggested. The categories habitus, social field and capital are presented in an attempt to understand the informational practices built at the cross-roads between social relationships based on exploitation of one class by another (and the domination of one group by another) and the subjective perceptions of individuals.
\end{abstract}

Keywords: Method. Informational practices. Information users.

\footnotetext{
1 Mestranda, Universidade Federal de Minas Gerais, Escola de Ciência da Informação, Programa de Pós-Graduação em Ciência da Informação. Av. Antônio Carlos, 6627, Pampulha, 31270-010, Belo Horizonte, MG, Brasil. Correspondência para/Correspondence to: A.F.M. PINTO. E-mail: <biblioflavia@gmail.com>.

2 Professor Doutor, Universidade Federal de Minas Gerais, Escola de Ciência da Informação, Programa de Pós-Graduação em Ciência da Informação. Belo Horizonte, MG, Brasil.

Recebido em 21/5/2012, reapresentado em 2/7/2012 e aceito para publicação em 14/8/2012.
} 


\section{Introdução}

Este artigo é parte das reflexões realizadas durante a pesquisa de mestrado intitulada "Práticas informacionais dos professores da RME/BH ${ }^{3}$ no cotidiano de suas lutas". As inquietações desta pesquisa surgiram da leitura sobre a necessidade de se fortificar a pluralidade teórico-metodológica da área da Ciência da Informação e do subcampo dos estudos de usuários, em que ainda se desconsideram ou se secundarizam as contradições sociais como determinantes na realização das práticas informacionais pelos sujeitos (Araújo, 2008).

A própria Ciência da Informação surge como disciplina para legitimar o discurso da "sociedade da informação" como uma "nova sociedade" baseada na informação e no conhecimento, na qual, segundo seus defensores, a informação se torna insumo para os processos produtivos. Seus teóricos, na maioria das vezes, ocultam o fato de o desenvolvimento dessa disciplina ter ocorrido num determinado marco do capitalismo, cujas preocupações estavam voltadas para a indústria científica e militar, principalmente nos Estados Unidos (Freitas, 2001).

Nesse contexto, o objetivo é formular uma crítica sobre o campo de usuários da informação, contribuindo, assim, com sua ampliação conceitual por meio da adoção de categorias da sociologia da prática, de Bourdieu. Entende-se que as categorias desenvolvidas por esse autor possibilitam uma compreensão das práticas informacionais dos sujeitos, considerando a dialética do conflito de classes (e de grupos dentro das classes) e a constituição subjetiva do indivíduo.

\section{Estudos de usuários da informação: entre o tradicional e $o$ alternativo}

O escopo da área de estudos de usuários da informação não é bem delimitado: abrange desde levantamento de empréstimos em bibliotecas até o comportamento informacional de um grupo de pessoas. Costuma-se dividir os estudos em "voltados para o sistema" ou "voltados para o usuário". Aqueles voltados para o sistema, de acordo com Figueiredo (1994), representam uma via de comunicação entre a biblioteca e a comunidade, além de serem instrumentos importantes para que bibliotecários avaliem a pertinência dos serviços prestados. Em geral, o questionário e a entrevista são os instrumentos de coleta de dados mais usados para empreender esses estudos. Nas palavras de Mostafa (1996, p.18), essa abordagem faz parte da aproximação positivista da Ciência da Informação, que:

[...] privilegia o SRI [Sistema de Recuperação da Informação] como um processo tecnológico, quase físico, onde são analisados os processos de registrar e recuperar informações e onde se fala também em usuários ou em pessoas, mas, em todo caso, esses usuários são concebidos como uma entidade que compõe o SRI, colocando- Ihes perguntas certas ou não e dele obtendo respostas relevantes ou não - usuário, apêndice do SRI, extensão do procedimento lógico das operações de registro e recuperação, sem intensionalidade política, um ser neutro, um apenas usuário.

Os estudos tradicionais, de bases funcionalista e behaviorista, voltados para diagnósticos da utilização de fontes de informação e serviços de informação, objetivam o funcionamento ótimo desses serviços, sem buscar a historicidade da sua existência e a compreensão sobre seu papel na sociedade. Obter um modelo de comportamento informacional é necessário para a previsão das ações dos sujeitos, objetivando o funcionamento ideal da organização. Dessa maneira, o viés behaviorista se destaca ao determinar comportamentos como se as ações humanas fossem apenas da ordem do psicológico e situacional (Lima, 1994).

Almeida (2005) alerta sobre o fato de que, se esses estudos não estiverem integrados aos objetivos da instituição à qual a biblioteca está ligada, corre-se o risco de não oferecerem subsídios reais para a melhoria dos serviços prestados, representando desperdício de tempo e dinheiro. Salienta-se ainda que grande parte dos serviços de informação das instituições brasileiras não é avaliada. Dessa maneira, aprofunda-se o distanciamento desses serviços dos seus usuários, da realidade em que estão colocados, e a consequência disso é a subutilização desses serviços até o seu abandono. Percebe-se que essa maneira de se abordarem usuários de informação está ligada à visão funcionalista, ou seja, tanto os usuários quanto a

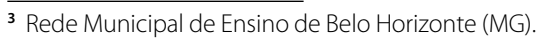


Unidade de Informação têm um significado em sua existência e fazem parte de um sistema social que precisa estar equilibrado como um corpo que funcione de maneira saudável. Tal modo de estudar usuários foi caracterizado por Capurro (2003) como o paradigma físico da Ciência da Informação.

Em busca de objetividade e credibilidade, os bibliotecários têm usado metodologias quantitativas para a fundamentação dos estudos de usuários (Lima, 1994). Cunha (1982) escreveu sobre os instrumentos de coleta de dados para a realização de estudos de usuários da informação, apresentando as vantagens e as desvantagens de cada ferramental metodológico, concluindo que a escolha da melhor metodologia dependerá dos objetivos do estudo que se deseja empreender. Também evidencia que os pesquisadores da área precisam aprimorar seus conhecimentos em relação à estatística e às técnicas de pesquisa social, além de buscar a teorização sobre conceito de demanda e necessidade de informação. Em outro artigo, publicado um quartel de século depois, Baptista e Cunha (2007) chegaram às mesmas constatações em relação aos ferramentais de coleta de dados, somando as novas metodologias voltadas para o usuário, denominadas, por Capurro (2003), como parte de um paradigma cognitivo ou alternativo da Ciência da Informação.

A vertente cognitivista, apesar de crítica aos estudos tradicionais, reproduziu certo mecanicismo na maneira de ver a realidade, ao considerar o "usuário" como um "processador de informações". A apreensão da informação na dimensão cognitiva está presente em Belkin (1980), Taylor (1986), Ellis (1989), Kuhlthau (1991), Dervin (1998), Wilson (2000) e outros. Em geral, esses pesquisadores partem da ideia de lacuna cognitiva gerada pela ausência de informações sobre determinado tema ou situação. Para o preenchimento dessa lacuna, os indivíduos precisam de informações que atendam suas necessidades.

Entre os pesquisadores dessa vertente, Taylor (1986) abordou as "dimensões situacionais" da necessidade e do uso da informação. Seus estudos foram realizados com empresários e alguns profissionais, e, segundo sua teoria, cada ambiente apresentará um tipo de problema e os grupos partilham os pressupostos sobre a natureza de seu trabalho e sobre o papel que as informações podem nele desempenhar. Não se vê, nas explicações de Taylor, atenção às disputas, ao controle da informação, que pode ser exercido por interesse de uma determina pessoa ou grupo, e não se vê também a posição que a organização ocupa na estrutura social, seu papel e o que isso pode significar na geração e no uso de informações no seu cotidiano. O contexto, para Taylor, é apenas a realidade funcional da empresa, uma "variável interveniente" nos processos de aumento de produtividade.

Nos estudos de Wilson (2000), outro pesquisador identificado com a vertente cognitivista, encontra-se a ideia de realidade social como construída a partir da "aparência" que o mundo tem para os indivíduos. Parece que, para o autor, a realidade social é construída individualmente, o que leva a entender que podem existir várias realidades e não uma única realidade construída historicamente pelas pessoas. Ele também não considera as relações conflituosas, marcadas pelo empoderamento de determinados grupos em detrimento de outros. Marx e Engels (2002, p.123) já afirmavam, em "Ideologia Alemã", que "a essência humana não é uma abstração inerente a cada indivíduo. Na realidade, ela é o conjunto das relações sociais". Não basta, assim, tentar entender o sujeito num ambiente estático e isolado de outras determinações do mundo.

Contudo, foi significativa a contribuição de Wilson (2000) ao considerar que as necessidades de informação estão ligadas aos "papéis" que os indivíduos desempenham na sociedade, além de considerar que essas necessidades apresentam dimensões socioculturais, político-econômicas e físicas. Nesse sentido, Wilson (2000) superou a leitura dos "cognitivistas" que consideravam a necessidade voltada para o desempenho de determinada tarefa, e essa necessidade geradora de uma lacuna da mente, como se fosse possível o pensamento da pessoa se tornar um vazio.

Choo (2003, p.82) desenvolve um "modelo multifacetado de uso da informação", considerando as várias dimensões dos sujeitos. Todavia, não supera o caráter behaviorista e funcionalista que marca os estudos de usuário da informação porque tenta construir um método que dê conta de prever o comportamento das pessoas a partir de um modelo de uso da informação. O autor avança no sentido de defender a interdisciplinaridade para as pesquisas do campo, ao considerar as múltiplas determinações nas construções de significado entre os 
indivíduos, mas se mantém no mesmo patamar dos estudos anteriores ao considerar a mesma maneira de olhar o usuário da informação a partir do viés comportamentalista. "Embora os comportamentos individuais em relação à informação possam apresentar uma variedade infinita, pode-se encontrar alguma ordem retirando as camadas cognitivas, emocionais e situacionais que envolvem a busca e o uso da informação" (Choo, 2003, p.83, grifo nosso).

Parece ser necessário determinar um padrão de comportamento para que a busca e o uso de informação aconteçam da maneira mais eficaz possível, e gere conhecimento e a possibilidade de decisões rápidas para o bom desempenho da organização, com todo o processo ocorrendo de forma bastante relacionada e funcional, como um sistema onde todos os componentes precisam funcionar harmonicamente para o bom andamento da organização (empresa, governo, universidade etc.) a fim de contribuir para a sociedade.

Essa concepção de estudos de usuário da informação faz parte de um paradigma funcionalista da Ciência da Informação, tecnologicamente determinado, que aborda o desenvolvimento da sociedade em todos os aspectos (político, social, econômico etc.) a partir do consumo de informações e das Tecnologias de Informação e Comunicação (TIC). Nessa perspectiva, torna-se necessário otimizar o acesso às informações para que as pessoas estejam mais conscientes de seus direitos e possam participar mais da democracia e fortalecê-la, para que se possa aperfeiçoar a produção de mercadorias ou para que o governo possa melhorar os serviços públicos. A resolução dos conflitos é "retirada" do âmbito das relações sociais e transferida para a disseminação das TIC.

Assim, ambos os modelos de estudos de usuário da informação, paradigma tradicional e alternativo, utilizam metodologias que ora fixam o olhar sobre o sistema de informação, ora sobre o usuário da informação. Dessa maneira, não apreendem a totalidade da história humana, das relações sociais e da relação do homem com a natureza. O homem é visto como uma entidade independente do mundo, um ser pensante com necessidades únicas, passível de sofrer influências da realidade externa. O homem é um ente e a sociedade outro ente; o que se nota dessa determinação é o estranhamento do homem em relação à concretude da realidade societal, refletido nos estudos desse campo da Ciência da Informação.

Nessa linha, Foskett (1980) assevera a necessidade de se fazer o estudo de usuários sem reduzir a psicologia do indivíduo ao entendimento do homem como uma unidade isolada e sem movimento. Assim, percebe-se a necessidade de se considerar a interconexão das coisas que envolvem o usuário, estudando detalhadamente cada parte sem desconsiderar o todo. Apesar dessa visão de totalidade em relação ao modo de abordar o objeto, suas preocupações estavam voltadas para a real compreensão das necessidades do usuário, com o objetivo de se ter o bom funcionamento da Unidade de Informação, ou seja, ele utiliza um dos elementos da dialética como um recurso metodológico para se empreender uma reflexão de concepção funcionalista: aprimorar o estudo da subjetividade do indivíduo, considerando as complexas relações que o envolvem, com o objetivo de melhorar o serviço de informação, de maneira que, para cada usuário, haja um serviço que atenda suas necessidades.

\section{A crítica metodológica como contribuição ao campo de usuários da informação}

A escolha de um objeto de pesquisa e do levantamento de questões a serem verificadas pressupõe um posicionamento que, assim como seu objeto, está situado historicamente em determinadas condições sociais. Para González de Gómez (2000, online, grifo nosso), a metodologia de pesquisa:

[...] designa, de maneira ampla, o início e a orientação de um movimento de pensamento cujo esforço e intenção direciona-se à produção de um novo conhecimento, num horizonte de possibilidades sociais e historicamente definidas. Os métodos, quantitativos, qualitativos, comparativos, assim como as técnicas de coleta e análise da informação, definem a direção e a modalidade das ações de pesquisa de modo secundário, estando já ancorados num domínio epistemológico epolítico que acolhe elegitima as condições de produção do objeto da pesquisa. Uma metodologia de pesquisa teria, para nós, e como primeira tarefa, a tematização dessas condições de produção do objeto de conhecimento. 
Concorda-se com González e Gómez (2000) que os ferramentais de coleta de dados devem servir à pesquisa que parte de um horizonte político e de bases epistemológicas definidos pelo pesquisador, ou seja, do seu posicionamento. Trata-se de entender que não há neutralidade na pesquisa. Para Almeida Júnior (2005, p.162), o pesquisador que se declara"isento" "não se compromete com os resultados ou com posicionamentos mais concretos e incisivos". Assim, tende a passar a ideia de que a explicação dada para a realidade observada é fruto daquilo que os dados possibilitaram ao pesquisador apreender e não do seu posicionamento político e teórico, de onde parte sua análise.

Outra questão é a dificuldade dos pesquisadores de abarcar ou de mesmo pressupor toda a complexidade que envolve os indivíduos em uma sociedade dividida em classes. Ao não conhecer profundamente métodos de coleta de dados, o pesquisador do campo de estudos de usuários muitas vezes confunde instrumentos de coleta de dados com método.

Existem tentativas de se empreender estudos a partir de ferramental metodológico alternativo, mas os pesquisadores não conseguem chegar a um resultado satisfatório ou não concretizam a aplicação da metodologia anunciada. Outros estudiosos buscam, nas teorias das Ciências Sociais, fundamentos para auxiliar nas análises dos dados, e conjugam tais fundamentos com as metodologias desenvolvidas na área, principalmente aquelas do campo cognitivo ${ }^{4}$.

As recentes tentativas de se buscar arcabouço teórico das Ciências Sociais contribuíram para o alargamento da visão do pesquisador sobre o objeto, na busca por interpretações além do escopo do uso de informação. Contudo, ainda pouco se tem discutido sobre as metodologias de modo a trazer contribuições teóricas para o avanço do campo de estudos de usuários da informação. Ainda é atual a afirmação de Lima (1994) sobre a existência de pouca reflexão entre bibliotecários e pesquisadores da área em torno dos métodos que podem ser usados para se buscar o entendimento da riqueza e da complexidade do indivíduo ou usuário da informação.

\section{A contribuição da sociologia da prática de Bourdieu para o estudo das práticas informacionais}

Diferentemente de "comportamento informacional", o estudo das práticas informacionais considera os significados atribuídos pelos sujeitos durante as ações de buscar, usar e disseminar informações nos "espaços constituídos e concretos de realização" de tais práticas (Marteleto, 1995, p.91). Essas práticas se realizam como construção social, com as múltiplas determinações constituídas nas relações capitalistas de produção.

Nesse sentido, a sociologia da prática de Bourdieu (1983) apresenta categorias de análise que podem auxiliar no entendimento da relação entre indivíduo, prática informacional e sociedade. Bourdieu (1983) desenvolveu várias categorias para analisar os campos científico, cultural, educacional, entre outros, buscando aliar e superar as categorias do objetivismo, da fenomenologia e do marxismo. Dessa maneira, ele buscou compreender as relações de disputa entre dominadores e dominados não só numa perspectiva econômica, como também a partir das marcas que essas disputas deixam na subjetividade das pessoas e que conformam a ação delas diante das situações do cotidiano, ou seja, Bourdieu incorpora a dimensão do simbólico, do cultural.

A primeira noção trazida por Bordieu é a de habitus, um produto das relações sociais que engendra a formação do indivíduo, conformando e orientando sua ação, num determinado contexto. O habitus se constitui em classificações que o indivíduo internaliza durante sua história de vida por meio da família (habitus primário), dos ambientes que frequenta e da sua formação escolar (habitus secundário). Tais classificações mantêm o sistema de dominação em dois sentidos: por meio do discurso ideológico e por meio da "categoria lógica que ordena a própria representação social" (Ortiz, 1983, p.16). Assim, o sujeito realiza suas ações ou faz suas escolhas a partir da dialética entre a situação vivida e o seu habitus, ou seja, o conjunto de ideias, gostos, maneiras de perceber o mundo, constituídos primeiro na família e depois na escola,

\footnotetext{
${ }^{4}$ Algumas aplicações recentes em estudos de usuários da informação buscam, nas teorias oriundas do campo das Ciências Sociais, como a etnometodologia e a fenomenologia, elementos para sustentar bases argumentativas, no sentido de se buscarem metodologias alternativas para análise de busca e uso da informação.
} 
por meio das relações sociais. "O habitus como sistema de disposições duráveis é a matriz de percepção, apreciação e ação, que se realiza em determinadas condições sociais" (Ortiz, 1983, p.19). Para Bourdieu (1983), esse sistema garante a reprodução da ordem social antagônica e o campo (seja científico, artístico ou político) é o locus onde se dá a disputa entre os diferentes agentes, cada qual dispondo de seu capital específico para manter sua posição no campo, mas todos compartilhando das mesmas regras para realizar a disputa.

A noção de capital foi retomada de Marx por Bourdieu (1983), porém a categoria exploração, importante para o marxismo, uma vez que o capital é relação social constituída a partir da apropriação de mais-valia, foi suprimida (Burawoy, 2010). Para Bourdieu, o capital é o acesso a uma determinada quantidade de condições para um indivíduo ou grupo se posicionar num campo. Os dominadores possuem um máximo de capital - cultural, social, político, profissional, econômico, linguístico, simbólico e informacional. Os dominados detêm o mínimo desse capital. A esse acesso desigual que perpetua a relação de dominação, Bourdieu chamou de violência simbólica (Ortiz, 1983; Nascimento; Marteleto, 2004). Assim, o autor evidencia a disputa entre os próprios capitalistas, uma vez que, nesse campo, também existem dominadores e dominados - e não somente na relação entre capitalista e trabalhador -, porém desconsidera a relação de exploração quando debate a aquisição do capital cultural. Bourdieu (1983) tende a colapsar as relações de propriedade, de produção, de distribuição com o processo de trabalho, a divisão do trabalho e as relações produtivas. Dessa maneira, a teoria bourdieusiana acaba "reduzindo a divisão do trabalho a simples posse de um capital" (Burawoy, 2010, p.37).

As práticas dos sujeitos, cada um com suas percepções, gostos e maneiras de entender a realidade, internalizadas pelo habitus, mantêm o habitus coletivo e alimentam a construção do campo. O campo é o lugar estruturado pelas ações, representações e relações sociais, a "estrutura objetiva que define as condições sociais de produção do habitus" (Bourdieu, 1983, p.65).

"O conceito de campo serve para construir a informação como expressão cultural de sujeitos posicionados pela estrutura" (Nascimento; Marteleto, 2004, online, grifo nosso). Bourdieu (1998, p.160) lembra que"efetivamente, o espaço social se retraduz no espaço físico". Novamente em Nascimento e Marteleto (2004, online), o espaço social aparece "atrelado à posse das diferentes espécies do capital e da distância física de bens ou serviços, também dependente do capital".

Na visão de Bourdieu, há um consenso entre dominantes e dominados, e a disputa travada entre os agentes não levará a uma transformação, pois a sociedade é compreendida por ele como "estratificação do poder" (Ortiz, 1983, p.26). Aliás, Bourdieu não se debruçou sobre a produção da desarmonia entre habitus e campo, o que poderia levar à transformação social.

A conformação da sociedade capitalista sujeita a classe trabalhadora ao ocultamento da exploração (alienação) por meio do fetichismo da mercadoria e da ideologia que conforma uma visão única de mundo, como se o capitalismo fosse eterno. Para Bourdieu, a constituição de um habitus profundo nos trabalhadores faz com que eles não percebam a relação de exploração à qual estão sujeitos (Burawoy, 2010).

Em Bourdieu, a violência simbólica exercida pelos dominadores sobre os dominados, a partir da internalização do habitus, conduz à mistificação da relação de classe fundada na dominação. A dominação simbólica"é marcada a ferro e fogo sobre a psique individual, ao passo que a hegemonia é o efeito das relações sociais nas quais os indivíduos estão inseridos" (Burawoy, 2010, p.93).

A dominação simbólica repousa na subjetivação da estrutura social nos corpos, com a formação de um habitus arraigado e inconsciente, ao passo que a hegemonia no ambiente de trabalho repousa sobre indivíduos inseridos em instituições específicas que organizam o consentimento à dominação - ela própria uma precondição para mistificação da exploração (Burawoy, 2010, p.93).

Ademais, segundo Bourdieu (1983), existe uma relativa autonomia dos campos sociais em relação às mudanças na política e na economia que acontecem na sociedade. Dessa maneira, as mudanças nos âmbitos políticos e econômicos não se transferem automaticamente para os campos sociais. Entretanto, Ortiz (1983) 
considera a importância da teoria de Bourdieu desde que seja relacionada à dinâmica da História, marcada por reproduções, mas também por transformações da realidade social.

Assim, as ações de se informar ou de se produzirem ou se disseminarem informações estão submetidas a essa dialética entre o habitus e a situação vivida que leva o sujeito a buscar, produzir ou disseminar informações. Isso acontece num campo social (seja a academia, a empresa, o campo sindical, artístico etc.) onde o sujeito ocupa determinada posição e utiliza do seu capital específico, no caso, o capital informacional, para a realização de suas práticas informacionais. Assim, as ações de produção, busca, recepção e apropriação das informações devem ser compreendidas a partir das posições ocupadas pelos sujeitos na estrutura social que determinam o quantum de capital informacional esses sujeitos dispõem para suas ações cotidianas.

Não se pode, obviamente, desconsiderar o elemento de alienação, fruto da relação de produção da sociedade capitalista, baseada na apropriação privada de trabalho excedente. Essas condições sujeitam os indivíduos a determinadas relações que visam à reprodução do status quo da sociedade burguesa. Desse modo, os donos dos meios de comunicação de massa possuem um capital informacional muito superior aos trabalhadores, e essa relação desigual se reproduz em outros espaços. Entre os próprios trabalhadores, um determinado grupo, detentor de maior capital informacional, num determinado contexto, pode exercer uma função de dominação em relação ao grupo com menor capital informacional. A relação dos trabalhadores com os dirigentes sindicais é um exemplo disso. A posição de dirigente sindical favorece o acesso a diversas informações que podem ser usadas para a manutenção de certos privilégios em relação aos demais trabalhadores.

Dessa maneira, ao partir das contradições sociais e das relações de empoderamento, aplicando-se as noções de habitus e de campo social, pode-se superar a tendência de mensurar comportamentos de busca, apropriação e disseminação da informação, buscando-se as contradições na realização das práticas informacionais pelos indivíduos.

\section{Conclusão}

O atual quadro teórico-metodológico do campo de estudos de usuários de informação apresenta-se limitado ao não considerar o sujeito como ser contraditório e, portanto, unidade do diverso. Os estudos tradicionais desconsideram a apropriação subjetiva da informação, objetivando o diagnóstico de uso das fontes e dos serviços de informação e desconsiderando as funções das organizações na estrutura social e na apropriação da informação pelos sujeitos.

Os estudos que se pautam pela abordagem cognitivista, ao desconsiderarem ou não problematizarem os aspectos sociais, chegam a resultados limitados, pois focam a tentativa de predeterminar comportamentos dos usuários. Dessa maneira, perdem-se os diversos elementos construídos socialmente que influenciam a formação da subjetividade dos indivíduos, ao mesmo tempo em que esses mesmos indivíduos atuam na modificação da realidade. Ao entender o indivíduo como um ser com lacunas, desconsidera-se esse movimento dialético entre indivíduo e realidade social, pois o objetivo é apenas construir sistemas que reproduzam o modo de pensar dos usuários.

Outros estudos que procuram entender o usuário a partir de um contexto limitam-se ao contexto da instituição ou de um grupo, sem considerar as relações conflituosas e as diferenças sociais impostas por uma sociedade dividida em classes, ou seja, sem partir da historicidade, totalidade e tensionalidade. Assim, por exemplo, quando se fala na gestão do conhecimento numa empresa, funcionários, gestores e patrões são vistos como "iguais", cada um dispondo de um conjunto de informações ligadas à natureza de sua função, e se desconsideram as diferenças de posse de informação em relação ao lugar ocupado pela pessoa na empresa.

Nessa perspectiva, entende-se que a Ciência da Informação e os estudos de usuários podem buscar, na Sociologia da prática de Pierre Bourdieu, as categorias campo, habitus e capital para possibilitar uma análise das práticas informacionais que alie as condições objetivas da sociedade (a relação de produção que determina a estrutura social) e as apropriações subjetivas dos indivíduos. 


\section{Referências}

ALMEIDA, M.C.B. Planejamento de bibliotecas e serviços de informação. 2.ed. Brasília: Briquet de Lemos, 2005.

ALMEIDA JÚNIOR, O. Sobre os métodos e as técnicas de pesquisa: reflexões. In: VALENTIM, M.L.P. (Org.). Métodos qualitativos de pesquisa em ciência da informação. São Paulo: Polis, 2005. p.161-171.

ARAÚJO, C.A.A. Estudos de usuários: pluralidade teórica, diversidade de objetos. In: ENCONTRO DA ASSOCIAÇÃO NACIONAL DE PESQUISA E PÓS-GRADUAÇÃO EM CIÊNCIA DA INFORMAÇÃO, 9., 2008, São Paulo. Anais eletrônicos... São Paulo: Ancib, 2008. 1 CD-ROM.

BAPTISTA, S.G.; CUNHA, M.B. Estudo de usuários: visão global dos métodos de coleta de dados. Perspectivas em Ciência da Informação, v.12, n.2, p.168-184, 2007.

BELKIN, N.J. Anomalous states knowledge as a basis for information retrieval. The Canadian Journal of Information Science, v.5, p.133-143, 1980.

BOURDIEU, P. Esboço de uma teoria da prática. In: ORTIZ, R. (Org.). Pierre Bourdieu: sociologia. São Paulo: Ática, 1983. p.46-81.

BOURDIEU, P. (Coord.). A miséria do mundo. 2.ed. Petrópolis: Vozes, 1998.

BURAWOY, M. O marxismo encontra Bourdieu. Campinas: Unicamp, 2010.

CAPURRO, R. Epistemología y ciencia de la información. In: ENCONTRO NACIONAL DE PESQUISA EM CIÊNCIA DA INFORMAÇÃO, 5., 2003, Belo Horizonte. Anais... Belo Horizonte: Ancib, 2003.

CHOO, C.W. A organização do conhecimento: como as organizações usam a informação para criar significado, construir conhecimento e tomar decisões. São Paulo: Senac, 2003.

CUNHA, M.B. Metodologias para estudo dos usuários de informação científica e tecnológica. Revista de Biblioteconomia de Brasília, v.10, n.2, p.5-20, 1982.

DERVIN, B. Sense-making theory and practice: an overview of user interests in knowledge seeking and use. Journal of Knowledge Management, v.2, n.2, p.36-46, 1998.

ELLIS, D. A bihavioral approach to information retrieval system design. Journal of Documentation, v.45, n.3, p.171-212, 1989.
FIGUEIREDO, N.M. Estudos de uso e usuários da informação. Brasília: Ibict, 1994

FOSKETT, D.J. Psicologia do usuário. In: FOSKETT, D.J. et al. A contribuição da psicologia para o estudo dos usuários da informação técnico-científica. Rio de Janeiro: Calunga, 1980. p.11-30.

FREITAS, L.S. Na teia dos sentidos: análise do discurso da ciência da informação sobre a atual condição da informação. 2001. Tese (Doutorado em Ciência da Informação) - Universidade de São Paulo, Escola de Comunicação e Arte, São Paulo, 2001

GONZÁLEZ DE GOMÉZ, M.N. Metodologia da pesquisa no campo da ciência da informação. Datagramazero, v.1, n.6, 2000. Disponível em: <http://dgz.org.br>. Acesso em: 12 jun. 2010

KUHLTHAU, C.C. Inside the search process: information seeking from the user's perspective. Journal of the American Society for Information Science, v.42, n.5, p.361-371, 1991.

LIMA, A. Aproximação crítica à teoria dos estudos de usuários de bibliotecas. Londrina: Embrapa, 1994.

MARTELETO, R.M. Cultura informacional: construindo o objeto informação pelo emprego dos conceitos de imaginário, instituição e campo social. Ciência da Informação, v.24, n.1, p.89-93, 1995.

MARX, K.; ENGELS, F. A ideologia alemã: seguido das teses sobre Feuerbach. São Paulo: Centauro, 2002.

MOSTAFA, S.P. Enfoques paradigmáticos da bibliotecologia; unidad na diversidad ou diversidad na unidad. Investigacion Bibliotecologica, v.10, n.21, p.18-21, 1996.

NASCIMENTO, D.M.; MARTELETO, R.M. A informação construída nos meandros dos conceitos da teoria social de Pierre Bordieu. DataGramaZero, v.5, n.5, 2004. Disponível em: <http:// www.dgz.org.br>. Acesso em: 12 jun. 2010.

ORTIZ, R. Introdução: a procura de uma sociologia da prática. In: ORTIZ, R. (Org.). Pierre Bourdieu: sociologia. São Paulo: Ática, 1983. p.7-36.

TAYLOR, R.S. Value-added processes in information systems. Norwood: Ablex, 1986.

WILSON, T.D. Human information behavior. Information Science Research, v.3, n.2, p.49-55, 2000. 